\title{
A inovação no Brasil a partir dos anos 2000: um alerta a partir da teoria neoschumpeteriana
}

Herton Castiglioni Lopes*

Resumo: o trabalho objetiva analisar a inovação na indústria brasileira a partir do período de 1998-2000, quando começam a ser publicados dados da PINTEC do IBGE. A luz da teoria neoschumpeteriana, as conclusões apontam que o desempenho inovativo observado pode se tornar incapaz de permitir ao país seguir uma trajetória sustentável de crescimento que o coloque em convergência com os países avançados. Observam-se indícios de que o crescimento econômico brasileiro pode estar muito mais relacionado à disseminação da quinta revolução tecnológica.

Palavras-Chave: Inovação, desenvolvimento, neoschumpeterianos, indústria brasileira.

Classificação JEL: O10; O30; O50

* Professor Adjunto da UFFS. E-mail: herton.lopes@uffs.edu.br 


\section{Introdução}

Diferentes trajetórias de desenvolvimento podem ser traçadas para o Brasil ao longo de sua história. No período contemporâneo, após o colapso dos anos 1980 e 1990, o Brasil vem apresentando melhores indicadores de crescimento. Do final dos anos 1970 ao final dos anos 1990 o crescimento foi praticamente insignificante, sendo retomado de forma equilibrada apenas na virada do século passado (Figura 1). Este último período, para alguns, parece inaugurar uma nova onda de desenvolvimento (novo-desenvolvimentismo1), com uma trajetória quase ininterrupta de crescimento do PIB per capita.

Figura 1: Evolução do PIB per capita do Brasil (1900-2012)

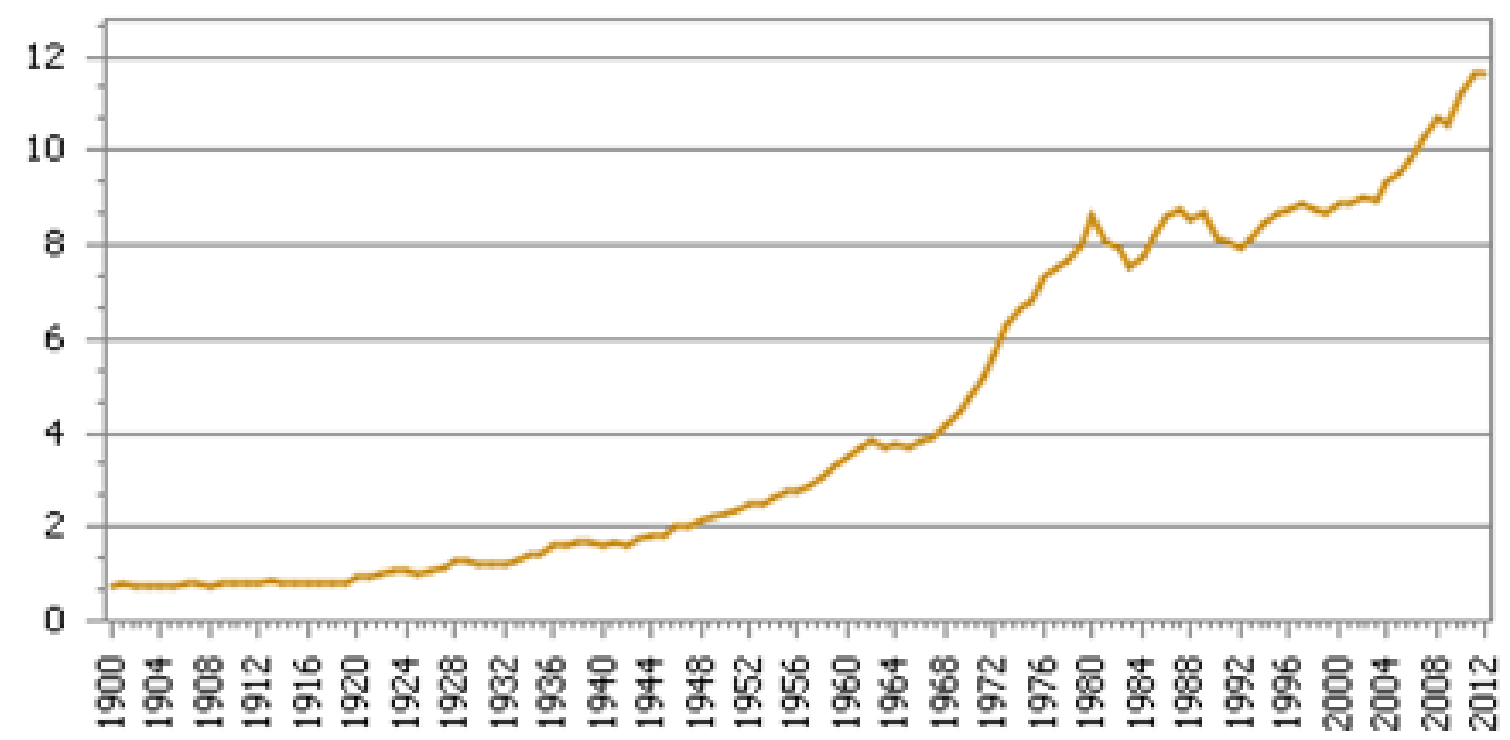

Fonte: Ipeadata (2013)

De acordo com a abordagem neoschumpeteriana, os ciclos de desenvolvimento são explicados pelo dinamismo das inovações, que rompem com as condições produtivas existentes, geram mudança tecnológica, estrutural e institucional, trazendo ganhos de produtividade que se alastram pela economia. Em função disso, a necessidade de observar a inovação na indústria brasileira no período em que se retoma o crescimento econômico se torna evidente. Esta é a proposta desse ensaio, que objetiva integrar a teoria microeconômica evolucionária com o conceito de revoluções tecnológicas para tecer algumas reflexões críticas sobre o processo inovativo na indústria brasileira. Para isso, utilizam-se alguns indicadores publicados pela Pesquisa de Inovação Tecnológica (PINTEC) $)^{2}$ do IBGE.

\footnotetext{
1 A tese novo-desenvolvimentista surge nos trabalhos de autores brasileiros como Bresser-Pereira (2004), BresserPereira e Nakano (2002, 2003) e Bresser-Pereira e Gala (2007) e argentinos (ver Silva, 2013), assim como repercute em toda América Latina. Essa nova fase de desenvolvimento se diferencia do ideário neoliberal e do antigo desenvolvimentismo, por incorporar a noção de que o desenvolvimento carece de um mercado forte (iniciativa privada) com um estado forte, capaz de colocar em prática uma estratégia nacional de desenvolvimento.

2 Como se trata de um ensaio, com limitação de páginas, optou-se por não reproduzir a metodologia de Pesquisa da PINTEC. Maiores informações podem ser obtidas diretamente no site: http://www.pintec.ibge.gov.br.
} 
Se uma suposição tivesse de ser imediatamente exposta, seria a de que os indicadores de inovação vêm evoluindo positivamente no período em questão, dando sustentação à melhor performance da década de 2000. Porém, a teoria evoluída de Schumpeter permite que se levantem questionamentos sobre o processo inovativo brasileiro e sua capacidade de promover o catching up do país frente aos avanços tecnológicos que são recorrentes nas economias capitalistas avançadas. Por isso, o desempenho inovativo deve ser analisado com cautela, principalmente porque a teoria demonstra ser o caso dos países em desenvolvimento bastante paradigmático e dependente das oportunidades que se abrem em cada revolução tecnológica.

Por se tratar de um ensaio, que procura fazer um alerta para necessidade de uma reflexão crítica sobre eficácia do processo inovativo brasileiro, o texto apresenta-se condensado em duas seções. Inicialmente integra-se a abordagem microeconômica evolucionária com os conceitos de revoluções tecnológicas e seus desdobramentos. Em seguida trata-se da inovação na indústria brasileira a partir do período 1998-2000.

\section{A abordagem neoschumpeteriana: a teoria microeconômica evolucionária e as revoluções tecnológicas}

Na teoria de Schumpeter as inovações são tratadas como um fenômeno interno ao modo de produção, fundamentais para explicar os períodos de boom e depressão econômica. Ou seja, os ciclos recorrentes do sistema capitalista (Schumpeter, 1984, 1985). Sendo precursor na análise da relação entre inovação e desenvolvimento, Schumpeter abre um campo fértil de pesquisa que tem continuidade em diversos autores, não por acaso denominados neoschumpeterianos.

Seguindo a tradição evolucionária, os neoschumpeterianos incorporam conceitos da biologia para explicar o desenvolvimento, priorizando uma análise crítica e diferenciada em relação a tradição ortodoxa. No âmbito microeconômico, Richard R. Nelson e Sidney G. Winter são autores referência quando se trata desse tipo de exposição. Em 1977, na obra "In search of useful theory of innovation", os autores começaram a desenvolver conceitos que se tornariam marco conceitual no livro "An Evolutionary Theory of Economic Change", publicado em 1982. Traçando paralelos com os conceitos provindos da biologia os autores demonstram serem as firmas os organismos individuais (fenótipos), sujeitos a um processo de seleção e adaptação. Os mercados ou indústrias são a população, o lócus onde acontece a seleção dos mais aptos. As empresas mais competitivas, ou seja, aquelas com maior grau de adaptação, crescem e ganham parcela mais significativa do mercado. Essa competitividade se manifesta através das rotinas das empresas (seus genes) e da sua capacidade de inovação (elemento de mutação), que age alterando os hábitos produtivos estabelecidos.

Desta forma, as firmas, suas rotinas e capacidade de inovação, estão sujeitas a um processo evolucionário. Firmas com rotinas mais adequadas serão as 
com maior possibilidade de sobrevivência e com maiores chances de crescimento (aquisição de market share). Como contemplam as análises evolucionárias, esse processo é determinado historicamente. As rotinas acumuladas e o conhecimento presente no interior das empresas são resultado de um processo de aprendizagem que acontece quando as firmas procuram solucionar os problemas do processo de produção (Zawislac, 1996). O conhecimento, a inovação e geração de novas rotinas permite o progresso das técnicas que, socialmente, também está sujeito a um processo evolucionário (Nelson, 2007).

A esta dinâmica microeconômica, os autores neoschumpeterianos incorporam uma diversidade de análises, tais como o papel do estado no estímulo à reestruturação das empresas e progresso técnico (Pérez, 1992), a importância do sistema nacional de inovações, como elemento para o arranque e disseminação das inovações (Conceição, 2012; Nelson, 2007), a eficácia das instituições econômicas no processo seleção das inovações mais condizentes com o padrão de crescimento da nação (Nelson, 1988; Pérez, 1983), entre outras questões que fogem ao escopo desse trabalho. Apesar da amplitude conceitual, quando se procura analisar a inovação como fonte das desigualdades entre os países e se desprende da abordagem microeconômica e concorrencial, o conceito de revoluções tecnológicas é elemento de expressiva relevância.

Em conjunto com Christopher Freeman, Carlota Pérez passou a analisar o desenvolvimento a partir das inovações radicais que permitem aos países saltos qualitativos de desenvolvimento (Velho, 2010). O modelo Freeman-Pérez (Conceição, 2001) traz conceitos semelhantes aos propostos por Abramovitz (1986), incorporando as possibilidades de algumas nações menos desenvolvidas avançarem (forging ahead) e alcançarem as de ponta (catching up), enquanto outras acabam sendo ultrapassadas (falling behind) ${ }^{3}$. É uma abordagem mais macroeconômica para inovação, onde o catching up acontece a partir da revolução tecnológica e das oportunidades que surgem com novos paradigmas tecnoeconômicos.

Para Perez $(1992 ; 2001 ; 2004 ; 2009)$ o que determina as condições de desenvolvimento dos países é a sua capacidade em aproveitar as janelas de oportunidades que se abrem em cada revolução. Para a autora, uma revolução tecnológica é "un poderoso y visible conjunto de tecnologías, productos e industrias nuevas y dinámicas, capaces de sacudir los cimientos de la economía y de impulsar una oleada de desarrollo de largo plazo" (Pérez, 2004, p.32). Historicamente, foram cinco revoluções que moldaram as condições de produção no mundo: a revolução industrial, a era do vapor e das ferrovias, a era do aço e da eletricidade; a era do automóvel e da produção em massa; a era da informática e da sociedade do conhecimento. A revolução tecnológica define o paradigma tecnoeconômico, entendido um guia para se aproveitar ao máximo as potencialidades abertas pela revolução em curso. Ele estipula novas práticas coletivas (práticas ótimas), que servem para orientar as decisões de todos os agentes ligados ao processo produtivo.

A quinta revolução tecnológica, a era da informática e das telecomunica-

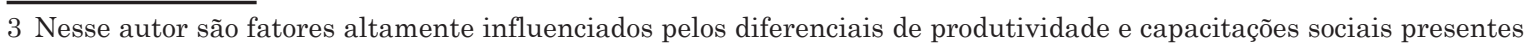
em cada instante. 
ções, iniciou-se nos anos 1970 nos EUA (disseminando-se pela Europa e Ásia). A partir microeletrônica, surgiram novas tecnologias e novas indústrias. Essa revolução criou a necessidade de nova infraestrutura (comunicação digital, novas redes elétricas e de transporte) e disseminou um novo paradigma tecnoeconômico que, baseado no uso intensivo da informação, alterou a forma de operação das empresas e estabeleceu os rumos para inovação tecnológica.

Diante dessas observações, a inovação nos países em desenvolvimento não pode restringir-se a concepção microeconômica, mas integrar o conceito de revoluções tecnológicas e seus desdobramentos. Para os países emergentes, a inovação (e o progresso técnico que ocorre no âmbito microeconômico) deve viabilizar o ingresso, com êxito, na revolução tecnológica em curso. O crescimento das inovações deve acontecer no momento em que se abrem as janelas de oportunidade de cada revolução. Isto porque as tecnologias passam por uma trajetória e, nos seus últimos anos, entram em uma fase de maturação. Por isso, os países devem aproveitar-se das primeiras fases do boom tecnológico, quando os mercados são crescentes e a lucratividade é elevada.

\section{A inovação na indústria brasileira a partir dos anos 2000: uma análise a partir da teoria neoschumpeteriana}

Há muito se desconfia que a qualidade e a intensidade do processo de inovação tecnológica, que ocorre na empresa brasileira, desempenham papel central na explicação das razões da limitada performance da produtividade do trabalho (Viotti, 2005, p. 955)

O maior nível de desenvolvimento observado no Brasil dos últimos anos levaria a conclusão de que os indicadores de inovação tem evoluído positivamente ao longo dos anos 2000. De fato, no âmbito microeconômico, com exceção do período pós crise de $2008^{4}$, alguns indicadores vêm apresentando bons resultados. Na indústria brasileira (extrativa e de transformação), a taxa de inovação (número de empresas inovadoras em relação ao total) aumentou de $31,52 \%$ no período de $1998-2000$ para $37,84 \%$ em $2006-2008$, porém, reduziu-se para $35,56 \%$ em $2009-2011$.

Sob o ponto de vista de atuação das empresas, o esforço inovativo mostra-se intensificado. Os dados da PINTEC apontam que o esforço individual se destaca quando comparado à outras fontes de inovação ${ }^{5}$. No período de 1998 2000, 35,6\% das empresas afirmaram ser a principal fonte da inovação. Esse percentual sobe para 42,9\% em 2003-2005 e sofre pequena redução em 20092011 (40\%). O mesmo vale para os gastos em atividades inovativas e o número de pessoas com dedicaçao exclusiva à atividades de inovação. No período de

\footnotetext{
$4 \mathrm{Na}$ abordagem de Pérez (2004) as crises financeiras são resultado das revoluções tecnológicas. Nos anos iniciais de uma revolução, o capital financeiro apoia o produtivo nos investimentos associados às novas tecnologias. No entanto, o comportamento frenético do capital faz surgir bolhas tecnológicas, que levam a um colapso financeiro.

5 As outras fontes de inovação captadas na pesquisa são: outra empresa do grupo, redes de cooperação, outras empresas ou institutos.
} 
1998-2000, o percentual de empresas com gastos em inovação representava 27\%, passando para 30\% em 2006-2008 e atingindo 36\% em 2009-20116. Já o número de pessoas com dedicação exclusiva à atividades de $\mathrm{P} \& \mathrm{D}$, apesar de pequeno, aumentou de uma média de 6 pessoas no período de 1998-2000 para 11 pessoas em 2006-2008, reduzindo-se um pouco em 2009-2011 (10 pessoas).

Como prega a teoria derivada de Schumpeter, as inovações são uma forma de modificar as rotinas, sobreviver à concorrência e ampliar a participação de mercado. Para isso, a maior parte das empresas segue o padrão tecnológico que se dissemina no país e realiza esforços inovativos de acordo com o paradigma tecnoeconômico em vigência. Não por acaso, o resultado das inovações se reflete em melhores indicadores de desempenho de mercado, conforme supõe a abordagem microeconômica evolucionária. O maior impacto das inovações segundo as empresas (indústria de transformação e extrativa) se expressa em três aspectos: a melhoria na qualidade dos produtos, a manutenção da participação do mercado e o aumento da capacidade produtiva.

Do ponto de vista microeconômico os indicadores de inovação estão evoluindo de forma aceitável, condizentes com a melhor performance dos últimos anos. No entanto, à luz da teoria neoschumpeteriana, que incorpora a análise do desenvolvimento a partir das revoluções tecnológicas (modelo Freeman-Pérez) e divide os países em líderes e seguidores (conforme teorizado em Abramovitz), tem-se que questionar sobre as possibilidades da inovação proporcionar um desenvolvimento ininterrupto, com indicadores que permitam ao Brasil aproximar-se dos países "de ponta". A esse respeito, um olhar mais cuidadoso sobre os dados de inovação demonstram que o melhor desempenho econômico dos últimos anos pode ser apenas resultado da difusão da quinta revolução tecnológica, que tende a transbordar métodos de produção arcaicos para os países menos desenvolvidos. A ideia de Carlota Pérez sobre a debilidade dos países em desenvolvimento de acompanhar a evolução tecnológica dos países avançados começa a fazer sentido quando se observa que grande parte das firmas responsabilizaram outros agentes (outras empresas ou institutos pesquisa) pela inovação (51,3\% no período 2006-2008). A teoria ganha ainda mais relevância quando conclui-se que uma grande parte das inovações ocorridas no Brasil dos últimos anos aconteceram em empresas de capital estrangeiro. Em 2005, do total de empresas industriais nacionais pesquisadas pela PINTEC, apenas $33 \%$ eram inovadoras. Esse percentual era de 66\% nas empresas industriais estrangeiras.

Tais evidências reforçam a ideia de que o desenvolvimento de capacitações internas e que gera endogenia no processo de desenvolvimento, pouco tem avançado na revolução da microeletrônica, sendo a maior parte das inovações dependentes de tecnologias externas. Exatamente por isso, as empresas destacam a aquisição de capital físico como fator imperativo para as inovações. No período de 1998-2000, 55\% das empresas pesquisadas pela PINTEC atribuíram alta importância a compra de máquinas e equipamentos como fonte inovativa. Esse percentual evolui para 61\% no período de 2005-2008.

A história não se repete de forma absolutamente análoga, mas, com

6 O valor médio investido pelas empresas em inovação era $\mathrm{R} \$ 1.166,00$ no período de $1998-2000$, passando a $\mathrm{R} \$ 1.725,00$ em 2003-2005 e reduzindo-se para $\mathrm{R} \$ 1,227,00$ em 2009-2011. 
certeza, mantém certas regularidades ${ }^{7}$. Se as empresas estrangeiras são as maiores inovadoras e a simples aquisição de máquinas e equipamentos a grande fonte inovativa, não espanta o fraco desempenho das atividades internas de Pesquisa e Desenvolvimento (no período 2009-2011 apenas 8\% das empresas pesquisadas atribuíram alta importância as atividades internas de P\&D como fonte da inovação ao passo que para $89 \%$ a importância era baixa ou a firma simplesmente não realizou tais atividades). Para piorar a situação, observa-se que as inovações (de produto e processo) que são "novas" para o mercado no qual a empresa atua representam uma parcela muito pequena das inovações (apenas para $12 \%$ das empresas inovadoras). Por outro lado, sobrepõem-se as inovações que são novidade para as empresas (para 88\% das pesquisadas). Isso demonstra que são técnicas de produção que já estavam sendo utilizadas, mas não eram do conhecimento da suposta inovadora.

A falta de autonomia das empresas nacionais torna o desenvolvimento dependente da implantação de inovações que se desenvolvem no exterior e são importadas pelas empresas que atuam no Brasil. Por isso, o desempenho econômico dos últimos anos parece se relacionar muito mais com a difusão da quinta revolução tecnológica do que com o desenvolvimento de capacitações próprias. Como as revoluções duram em média 50 ou 60 anos, a disseminação de tecnologias da revolução dos anos 1970 está permitindo ao Brasil crescer a partir de técnicas que já estão em uso nos países desenvolvidos. Ou seja, estão entrando em maturação e com potencialidades de retorno cada vez menores.

Mais problemas e dúvidas emergem numa rápida comparação dos indicadores do país com dados internacionais. Enquanto no Brasil a taxa de inovação foi de 37,84\% em 2006-2008, na União Europeia (excluindo-se a Grécia) observa-se que 56,1\% das empresas pesquisadas realizaram inovações em termos de produto ou de processo. Na Alemanha a taxa de inovação chega a 80\%, em Luxemburgo 64,7\% e na Bélgica 58,1\%.

Essas questões colocam em cheque a possibilidade de um crescimento sustentado e a superação do famoso "stop and go" característico da nossa economia. A emergência de uma nova revolução tecnológica pode colocar o país em condições mais difíceis, já que inovações no âmbito das firmas necessitam seguir o paradigma tecnoeconômico, que normalmente se desenvolve nos países avançados. As novas tecnologias carecem ainda de infraestrutura adequada para que as inovações a elas associadas possam ser colocadas em prática sem riscos de estrangulamento produtivo. Uma importante observação de Perez $(2001 ; 2004)$ é que as inovações em curso precisam criar as condições estruturais para continuidade do crescimento no caso de erupção de uma nova revolução tecnológica. Essa questão será colocada em evidência quando novas tecnologias revolucionarem as condições de produção nos países desenvolvidos. O risco para o Brasil é de um novo falling behind, como já se observou na economia nacional entre os anos 1970 e 1990.

$\overline{7 \text { Arend (2009) }}$ demonstrou que a economia brasileira entrou no paradigma de produção em massa na sua fase de maturação, o que permitiu 25 anos de catching up. Porém, nos anos 1980 e 1990 tardou a ingressar no paradigma da microeletrônica. Por ficar dependente de capitais e tecnologias externas, não conseguiu êxito ao ingressar na fase inicial do paradigma da microeletrônica, o que causou 25 anos de falling behind. 
Enfim, para o país avançar (forging ahead) e alcançar os países de ponta (catching up), não basta crescer com base no aproveitamento das tecnologias em fase de maturação. É preciso criar potencialidades internas e gerar aprendizagem, pois ela é a chave não apenas para as inovações que ocorrem nas fases de maturidade de um paradigma, mas principalmente quando da emergência de novas tecnologias.

\section{Considerações finais}

O ensaio procurou analisar criticamente a inovação na indústria brasileira a partir da teoria neoschumpeteriana. Observou-se que, apesar de alguns indicadores de inovação estarem evoluindo positivamente a partir dos anos 2000, a teoria neoschumpeteriana demonstra que o catching up das nações menos desenvolvidas relaciona-se com sua capacidade em aproveitar as oportunidades abertas em cada revolução tecnológica. A esse respeito, os dados sobre inovação indicam que o crescimento observado nos últimos anos pode estar muito mais relacionado ao processo de disseminação da quinta revolução tecnológica.

Essa forma de desenvolvimento e proliferação das inovações é bastante preocupante, pois, como aconteceu no passado, nada garante que o Brasil consiga ingressar de forma eficiente em uma nova revolução tecnológica. Se a endogeneidade do processo inovativo estiver comprometida, como apontam determinados indicadores, uma nova revolução pode condenar o país a alguns anos de falling behind, até que a próxima revolução crie tecnologias maduras, que se expandam para os países em desenvolvimento proporcionando um catching up tardio e debilitado.

Apesar de certas afirmações necessitarem de estudos mais aprofundados, principalmente em função das limitações de dados existentes, acredita-se que o paper tenha contribuído para alertar sobre os riscos da história se repetir e o crescimento futuro acabar comprometido pela falta de incentivos ao progresso técnico "de ponta". Nesse caso, cabe ao Estado formular uma verdadeira estratégia nacional de desenvolvimento, que proporcione o ingresso eficiente na próxima transição tecnológica.

\section{Referências Bibliográficas}

Abramovitz, M.(1986). Catching up, forging ahead and falling behind. Journal of Economic History, New York, v. 46, n. 2, p. 385-406.

Arend, M.(2009). 50 Anos de industrialização do Brasil: uma análise evolucionária. 2009. Tese (Doutorado em Economia) - Programa de Pós-Graduação em Economia, Faculdade de Ciências Econômicas, Universidade Federal do Rio Grande do Sul, Porto Alegre.

Bresser-Pereira, L.C .(2004). "Novo-Desenvolvimentismo”. Folha de S. Paulo, 2004. 
Bresser-Pereira, L.C..; Gala, P. (2007) Por que a poupança externa não promove crescimento. Revista de Economia Política, v. 27, n. 1: 3-19

Bresser-Pereira, L.C; Nakano, Y.(2002). Uma estratégia de desenvolvimento com estabilidade. Revista de Economia Politica , 21(3): 3-27.

Bresser-Pereira, L.C; Nakano, Y.(2003). Crescimento com poupança externa. Revista de Economia Política, 22(2): 3-27.

Conceição, O.A.C.(2001). Instituições, crescimento e mudança na ótica institucionalista. Porto Alegre: Fundação de Economia e Estatística Siegfried Emanuel Heuser (FEE).

Conceição, O.A.C.(2012). Há compatibilidade entre a "tecnologia social" de Nelson e a "causalidade vebleniana" de Hodgson? Revista de Economia Política, vol. 32, n 1 (126), p. 109-127.

IPEA (2012). Instituto de Pesquisa Econômica Aplicada. Brasília.

Nelson, R.; E Winter, S. G.(1982). An Evolutionary Theory of Economic Change. Cambridge: Harvard University Press.

Nelson, R.; E Winter, S. G.(1977). In search of useful theory of innovation. Research Police. Elsevier, vol. 6(1), pages 36-76. Janeiro, 1977.

Nelson, R. R.(2007). Economic Development from the perspective of evolutionary economic theory. Working paper series: Globelics.

Nelson, R. R.(1988). Institutions supporting technical change in the united states. IN DOSI, G et. All. Technical Change and Economic Theory. Laboratory of Economics and Management (LEM), Sant'Anna School of Advanced Studies, Pisa, Italy.

Pintec. Pesquisa Inovação Tecnológica. IBGE, 1998-2000; 2000-2002; 2003-2005; 2005-2008.

Perez, C.(1992). Cambio técnico, restructuración competitiva y reforma institucional en los países en desarrollo. El trimestre económico, México, v. 1, n. 233, p. 23-64, enero/marzo, 1992.

Perez, C.(1983). Cambio estructural y asimilación de nuevas tecnologías en el sistema económico y social. Futures. Vol. 15, No 4, Octubre, p. 357-375, (Tradução do inglês).

Perez, C.(2001). Cambio tecnológico y oportunidades de desarollo como Blanco móvil. Revista de la CEPAL, Santiago de Chile, n. 75, p. 115-136, dic.

Perez, C.(2004). Revoluciones tecnológicas y capital financiero: la dinâmica de las grandes burbujas financieras y las épocas de bonanza. México: Siglo XXI.

Perez, C.(2009). Technological revolutions and techno-economic paradigms. Working Papers in Technology Governance and Economic Dynamics, $n^{0} 20$. Technology governance.

Schumpeter, J. A.(1984) Capitalismo socialismo e democracia. Rio de janeiro: Fundo de Cultura.

Schumpeter, J. A.(1985). Teoria do desenvolvimento econômico. São Paulo: Nova Cultural. 
Silva, R. R. M.(2013). A construção política do novo desenvolvimentismo no Brasil e na argentina. VII Congreso Latinoamericano de Ciencia Politica, organizado por la Asociación Latinoamericana de Ciencia Política (ALACIP). Bogotá, setembro de 2013.

Velho, L.(2010). Apresentação ao texto "The determinants of innovation" de Christopher Freeman. Revista Brasileira de Inovação. Rio de Janeiro (RJ), 9 (2), p. 215-230, julho/dezembro 2010.

Viotti, E. B.(2005). Inovação tecnológica na industria brasileira: um exercício no uso de indicadores de inovação e algumas propostas para seu aperfeiçoamento. Parcerias estratégicas, Brasília, DF, n 20, jun. 2005. (Seminários temáticos para $3^{\circ}$ conferência Nacional de Ciência, Tecnologia e Inovação).

Zawislak, P.A.(1996). Uma abordagem evolucionária para casos de atividade de inovação no Brasil. Ensaios FEE. Porto Alegre, V. 17, nº 1, p. 323-353. 